\title{
The time course analysis of morphological changes induced by Chikungunya virus replication in mammalian and mosquito cells
}

\author{
A. GHOSH ${ }^{1}$, P. A. ALLADI ${ }^{2}$, G. NARAYANAPPA ${ }^{3}$, R. VASANTHAPURAM ${ }^{1}$, A. DESAI $^{*}$
}

\begin{abstract}
${ }^{1}$ Department of Neurovirology, ${ }^{2}$ Department of Neurophysiology and ${ }^{3}$ Department of Neuropathology, National Institute of Mental Health and Neurosciences, Bangalore - 560029, Karnataka, India
\end{abstract}

Received December 29, 2017; revised March 9, 2018; accepted September 20, 2018

\begin{abstract}
Summary. - Chikungunya virus (CHIKV), a re-emerging Alphavirus, causes chronic myalgia and arthralgia in infected individuals. However, the exact pathophysiology remains undefined till date. Virus induced time course changes in host cells at the ultrastructural level and host cytoskeleton have been reported for other alphaviruses such as Sindbis and Semliki Forest virus. Few studies have tried to delineate the same for CHIKV leading to some understanding of the replication process. Selective CHIKV infection of progenitor cells involved in muscle repair has been proposed as a cause of myalgia; albeit the outcome of infection on these cells has not been reported. With this background, we investigated CHIKV-induced time course changes in two cell lines - Aedes albopictus (C6/36) and murine myoblasts (C2C12) by transmission electron microscopy (TEM). CHIKV infection of C2C12 cells resulted in cell death, with cells exhibiting well defined apoptotic features. In contrast, mature virions were released from infected C6/36 cells without cytolysis. Double labelling of C2C12 cytoskeletal proteins - such as actin, tubulin and CHIKV revealed that viral nucleocapsids co-localized with these proteins during replication. As the infection progressed, CHIKV disrupted the normal organisation of these cell proteins. CHIKV-induced plasma membrane extensions were observed in infected cells, which so far have been reported only for Sindbis virus. This is a first report describing the time course of morphological changes occurring in host cells as a result of infection with CHIKV at the ultrastructural level. Apoptosis of myoblasts due to CHIKV infection could also be an important factor contributing to the recurrence of myalgia in CHIKV patients.
\end{abstract}

Keywords: Chikungunya; electron microscopy; confocal microscopy; C6/36; C2C12; actin; $\boldsymbol{\alpha}$-tubulin

\section{Introduction}

Alphaviruses (the family Togaviridae) are classified as either New World or Old World alphaviruses, based on the geographic location from which they were originally isolated. New World alphaviruses like Eastern equine encephalitis virus (EEEV), Venezuelan equine encephalitis virus (VEEV) and Western equine encephalitis virus (WEEV) typically cause fatal encephalitis in humans and other mammals, whereas Old World alphaviruses, such as Chikungunya

*Corresponding author. E-mail: anitasdesai@gmail.com; phone: +91-080-26995778.

Abbreviations: $\mathrm{CHIKV}=$ Chikungunya virus; $\mathrm{CPV}=$ cytopathic vacuole; p.i. $=$ post infection; $S F V=$ Semliki Forest virus; SINV = Sindbis virus; TEM $=$ transmission electron microscopy virus (CHIKV), O'Nyong-nyong virus (ONNV), Ross River virus (RRV), Semliki Forest virus (SFV) and Sindbis virus (SINV), cause a triad of fever, rash and arthralgia syndrome that is rarely fatal (Ryman and Klimstra, 2008). The disease symptoms for CHIKV are characterized by chills and fever, headache, nausea, persistent myalgia, poly-arthralgia and maculopapular rash (Solignat et al., 2009). CHIKV is transmitted among susceptible vertebrate hosts by mosquitoes; therefore, the virus replicates in mosquito and vertebrate tissues similarly. It is known that CHIKV establishes a persistent non-cytopathic infection in mosquito cells while resulting in an acute infection leading to apoptosis in mammalian cells (Li et al., 2013; Long and Heise, 2015). Although CHIKV has emerged as one of the most important arboviruses of public health significance over the past decade, yet, the disease pathophysiology has not been completely unravelled. 
As obligate intracellular parasites, viruses depend on host cells for their replication, which in turn, results in alterations in the cellular morphology. The virus induced morphological changes at the ultrastructural level have been documented to some extent for alphaviruses such as SINV and SFV (Grimley et al., 1972; Jose et al., 2017) but very rarely for CHIKV (Chen et al., 2013). Electron microscopy has long been employed to observe viruses and virus-induced morphological changes in host cells at the ultrastructural level.

On the other hand, the cytoskeleton has a fundamental role in the cell, which includes organizing the spatial arrangement of subcellular organelles, regulating cell dynamics and motility, providing a platform for interaction with neighbouring cells, and ultimately defining overall cell shape (Radtke et al., 2006; Wickstead and Gull, 2011). The three major cytoskeletal components: actin filaments, intermediate filaments and microtubules, are necessary for maintenance of cell shape, cell motility and intracellular transport. During replication, viruses are known to subvert the host cytoskeletal actin and microtubule transport systems in order to facilitate their journey through the entire cell (Radtke et al, 2006). The unfolding of virus-induced reorganization of cytoskeletal proteins over the course of infection has not been conclusively reported for CHIKV. Few studies have addressed the re-arrangement of cytoskeletal proteins in host cells due to infection with other alphavirus members - SINV and SFV (Laakkonen et al., 1998). However, these reports have not evaluated the modifications in cytoskeletal architecture as a result of viral infection in a time point pattern.

The present study was therefore designed to document contrasting morphological changes at defined time points at the ultrastructural level by transmission electron microscopy (TEM) in two CHIKV-infected cell lines - Aedes albopictus mosquito cell line, C6/36, which is known to get persistently infected and murine myoblast cell line, C2C12. In addition, time course evolution of changes in cytoskeletal proteins - actin and tubulin caused by CHIKV infection in C2C12 cells was studied using confocal microscopy.

\section{Materials and Methods}

Virus. CHIKV strain DRDE-06 (GenBank accession number: EF210157.2), which does not contain the A226V mutation in the E1 gene (Kumar et al., 2014) was used in this study. CHIKV was propagated in Vero cells grown in Dulbecco's Modified Eagle's Media (DMEM) (Gibco, USA). The titre of the stock CHIKV grown in Vero cells was $10^{7} \mathrm{PFU} / \mathrm{ml}$.

Cells. C6/36 cells were grown in Mitsuhashi and Maramorosch (M \& M) insect media (HiMedia Labs, India) and C2C12 cells were grown in DMEM. Complete growth media consisted of basal medium supplemented with 10\% fetal bovine serum (FBS) (Sigma, USA). Mammalian cell lines were allowed to grow at $37^{\circ} \mathrm{C}$ in a $5 \%$
$\mathrm{CO}_{2}$ incubator whereas mosquito cell line $\mathrm{C} 6 / 36$ was incubated at $27^{\circ} \mathrm{C}$.

Infection of cells at different time points with CHIKV. C2C12 and $\mathrm{C} 6 / 36$ cells were seeded at a density of $2 \times 10^{5}$ cells per $\mathrm{ml}$ on $35 \mathrm{~mm}$ tissue culture petri dishes for electron microscopy experiments. Cells were allowed to grow until $\sim 80 \%$ confluence. Infection of cells was performed using $1 \mathrm{MOI}$ of $\mathrm{CHIKV}$. The virus adsorption was allowed for $1 \mathrm{~h}$ at room temperature, following which the inoculum was withdrawn and cells were washed thrice with sterile media. One set of infected cells was fixed using freshly prepared glutaraldehyde ( $2.5 \%$ in $0.1 \mathrm{~mol} / \mathrm{l}$ phosphate buffer, $\mathrm{pH} 7.4$ ) for $20 \mathrm{~min}$ at room temperature. This time point was marked as $0 \mathrm{~h}$ post infection (p.i.). Fresh growth media was added to wells containing CHIKV infected cells and these cells were allowed to grow further. Cells were subsequently fixed at $6 \mathrm{~h}, 12 \mathrm{~h}, 18 \mathrm{~h}, 24 \mathrm{~h}$ and $30 \mathrm{~h}$ p.i. Infection was performed in triplicates for each time point and appropriate uninfected controls were included. For confocal microscopy, C2C12 cells were seeded at a density of $0.05 \times 10^{6}$ cells per ml on coverslips in a 24 well tissue culture plate until they reached $\sim 60 \%$ confluence. Cells were infected with $1 \mathrm{MOI}$ CHIKV as described earlier. Cells were fixed at 6 h, 12 h, 18 h, 24 h and 30 h p.i. with chilled $4 \%$ paraformaldehyde for $10 \mathrm{~min}$. Similar experimental setup and controls were included as described previously.

Concentration and purification of CHIKV followed by negative staining. Concentration of CHIKV was performed using a discontinuous sucrose gradient as described earlier (Das et al., 2009). Briefly, $5 \mathrm{ml}$ of $20 \%$ sucrose (w/v) made in GTNE buffer $(200 \mathrm{mmol} / \mathrm{l}$ glycine, $50 \mathrm{mmol} / \mathrm{l}$ Tris, $100 \mathrm{mmol} / \mathrm{l} \mathrm{NaCl}$ and $1 \mathrm{mmol} / \mathrm{l}$ EDTA) was carefully overlaid onto $2.5 \mathrm{ml}$ of $50 \%$ (w/v) sucrose prepared with the same buffer. Subsequently, $2.5 \mathrm{ml}$ of CHIKV obtained after polyethylene glycol (Sigma, USA) concentration was gently overlaid onto the discontinuous sucrose gradient and centrifuged at 28,000 rpm for $2 \mathrm{~h}$ at $4^{\circ} \mathrm{C}$ using a centrifuge (Sorvall, R100). The virus band at the inter-phase was collected and re-suspended in 10-12 volumes of phosphate buffered saline (PBS) ( $\mathrm{pH}$ 7.2). The virus was further concentrated by centrifugation at $28,000 \mathrm{rpm}$ for $2 \mathrm{~h}$ and the pellet was dissolved in fresh PBS and stored in $0.2 \mathrm{ml}$ aliquots at $-70^{\circ} \mathrm{C}$. Purified CHIKV was then stained with $2 \%$ aqueous uranyl acetate (TAAB Laboratory Equipment, UK) for $30 \mathrm{~s}$ and analysed under electron microscope.

Processing cell monolayers for electron microscopy. Cell monolayers that were fixed at defined time points post infection were washed twice with sterile phosphate buffer and post-fixed using $1 \%$ buffered osmium tetroxide (TAAB Laboratory Equipment, UK) for $1 \mathrm{~h}$ at room temperature. Step-wise dehydration was carried out in graded series of alcohol (70-100\%). Propylene oxide (Sigma, USA) was added followed by gentle swirling to detach the cell monolayer. The detached monolayers were transferred to $2 \mathrm{ml}$ microcentrifuge tubes for centrifugation at 2,000 rpm for $5 \mathrm{~min}$. Overnight infiltration of the pellets was performed with 1:1 - propylene oxide : resin (TAAB Laboratory Equipment) at room temperature on a rotor. Fresh infiltration of pellets was carried out with 1:3 - propylene oxide : resin for $1 \mathrm{~h}$ under similar conditions. Final infiltration of pellets was done 
using $100 \%$ resin for $2 \mathrm{~h}$. The pellet was embedded on moulds and polymerization was carried out at $60^{\circ} \mathrm{C}$ for $48 \mathrm{~h}$. Ultrathin sections (60 nm/600 $)$ were cut using an ultra-microtome (Leica UCT7, Germany). Sections mounted on copper grids were treated with saturated methanoloic uranyl acetate solution and $0.2 \%$ lead citrate (TAAB Laboratory Equipment) to acquire a contrast and were observed under a transmission electron microscope (Tecnai G2, FEI, USA).

Double labelling of cells for confocal microscopy. Cells grown on cover slips and fixed with $4 \%$ paraformaldehyde post infection were washed twice for $5 \mathrm{~min}$ with PBS. Cells were treated with $0.3 \%$ Triton $\mathrm{X}-100$ at $4^{\circ} \mathrm{C}$ for 5 min and blocked using $5 \%$ skimmed milk powder in PBS for $45 \mathrm{~min}$ at room temperature. For actin-CHIKV double labelling, cells were incubated with 1:500 dilution of anti-actin antibody (Sigma) overnight at $4^{\circ} \mathrm{C}$ followed by washing and addition of 1:100 dilution of $\mathrm{Cy} 3$ secondary conjugate (ThermoFisher Scientific, USA) for $2 \mathrm{~h}$ at $4^{\circ} \mathrm{C}$ in the dark. Coverslips were washed thrice with sterile PBS and cells were then incubated with anti-eastern equine encephalitis monoclonal antibody (1:100) (Chemicon, USA) for $3 \mathrm{~h}$. Anti-eastern equine encephalitis monoclonal antibody has been earlier reported to exhibit cross reactivity to CHIKV envelope region (Reddy et al., 2012). The coverslips were washed and incubated overnight with anti-mouse FITC conjugated secondary antibody (1:100) at $4^{\circ} \mathrm{C}$. Coverslips were washed five times with PBS in dark and mounted on glass slides for visualization under confocal microscope (Leica, DMIRE2-TCS, Germany). For $\alpha$-tubulin-CHIKV double labelling, cells were first incubated overnight with 1:100 dilution of anti-CHIKV antibody (IBT Bioservices, USA) followed by washing and later incubation with Cy3 secondary conjugate (1:100) for $2 \mathrm{~h}$ at $4^{\circ} \mathrm{C}$ in the dark. Coverslips were washed thrice using PBS. Cells were then incubated with 1:200 dilution of a-tubulin antibody conjugated to Alexa Fluor ${ }^{\circ} 488$ (Thermo Fisher Scientific, USA) for $3 \mathrm{~h}$ at $4^{\circ} \mathrm{C}$ in the dark. Coverslips were washed five times with PBS in dark and mounted on glass slides for visualization under confocal microscope.

\section{Results}

\section{Ultrastructural studies of CHIKV induced changes in C6/36 and C2C12 cells}

\section{Electron micrographs of CHIK virions}

Negative staining of purified CHIKV observed under electron microscope revealed that mature CHIK virions (DRDE-06) were spherical with an electron dense core surrounded by a contrasting envelope. The core measured $\sim 35 \mathrm{~nm}$ in diameter and the diameter of the entire particle was $\sim 58 \mathrm{~nm}$ (Fig. 1).

Morphology of uninfected C2C12 and C6/36 cells under electron microscope

Transmission electron micrographs of uninfected C6/36 cells showed that cells were polygonal with eccentric nuclei and a large number of vacuoles filled with granular and

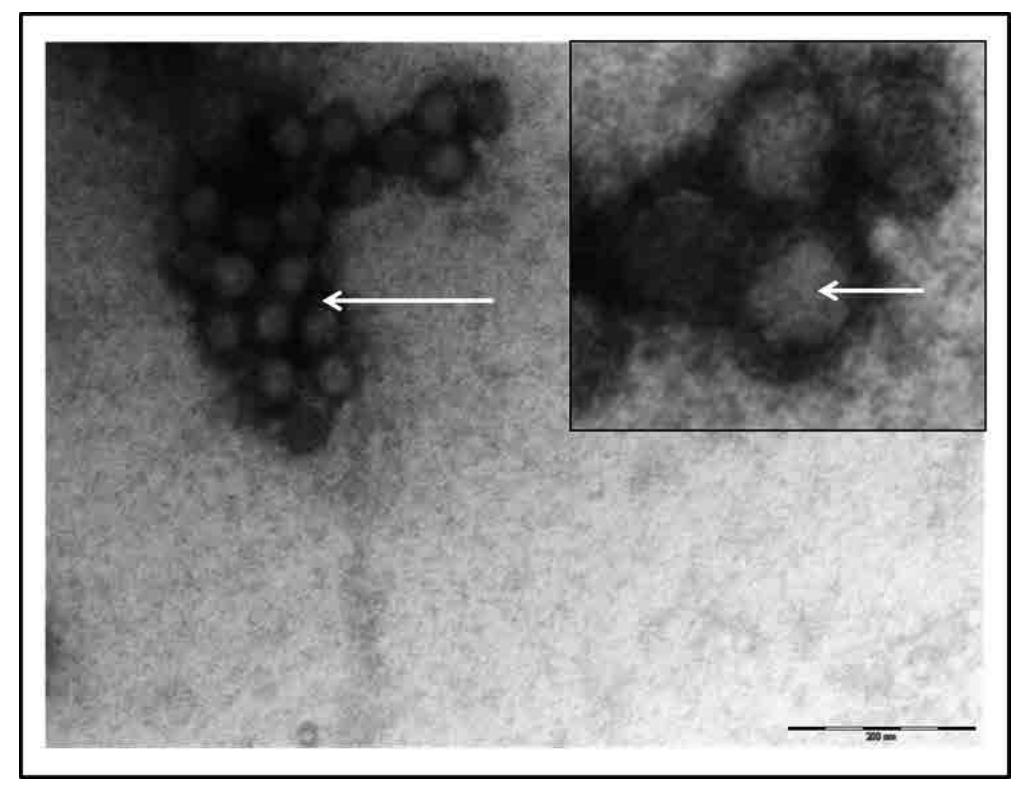

Fig. 1

Electron micrograph showing negatively stained CHIKV particles

Mature CHIK virions are spherical (arrow). Inset: higher magnification reveals that the lightly stained spherical core is surrounded by an electron dense envelope. Horizontal bar represents $200 \mathrm{~nm}$. 


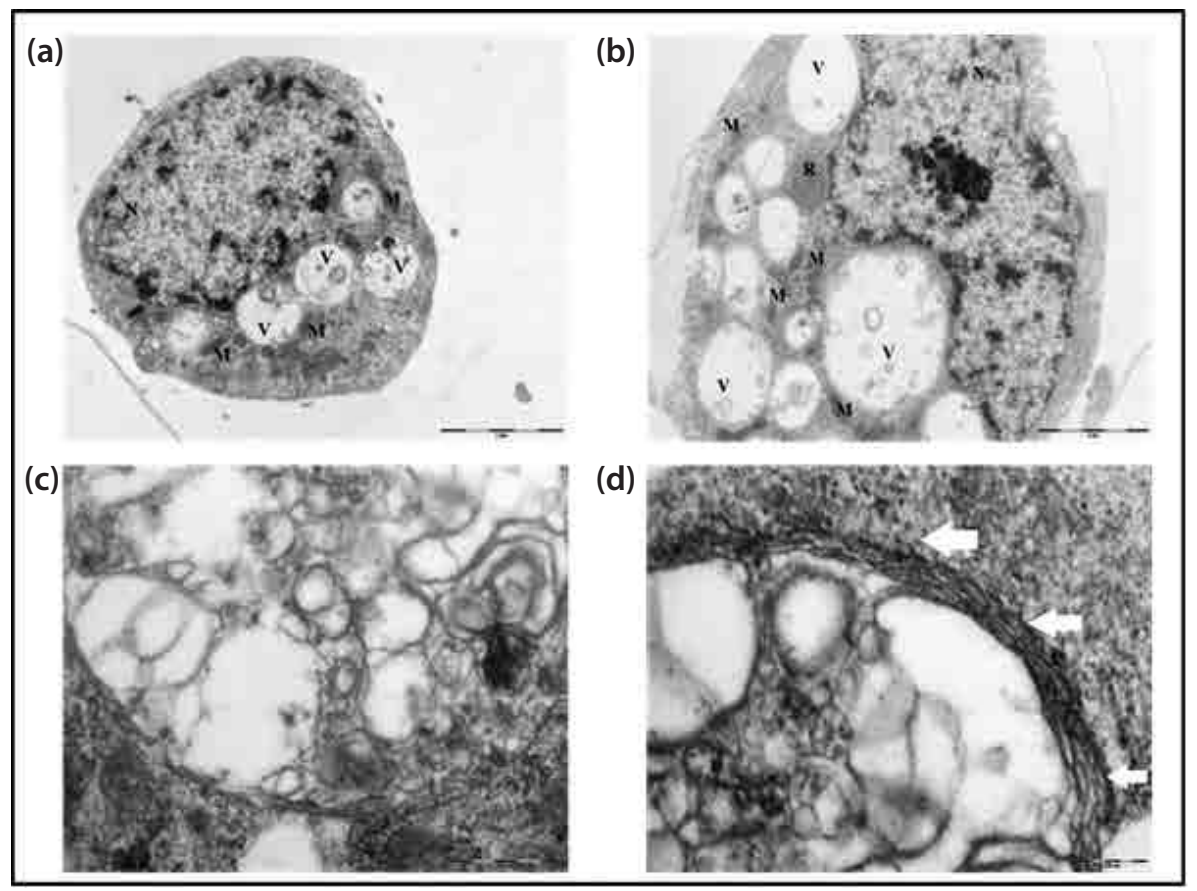

Fig. 2

Electron micrographs of normal C6/36 cell

(a) The cell contains an eccentric nucleus (N), mitochondria (M) and numerous vacuoles (V). Bar represents $2 \mu \mathrm{m}$. (b) Another cell showing numerous vacuoles, rough endoplasmic reticulum (R) in close proximity to the vacuoles and mitochondria. Bar represents $2 \mu \mathrm{m}$. (c) Higher magnification reveals that the vacuoles are packed with membranous whorled structures. Bar represents 500nm. (d) Note the Golgi network in apposition to the vacuole (white arrows). Bar represents $300 \mathrm{~nm}$.

whorled structures (Fig. 2). C2C12 cells on the other hand were spindle shaped with a centrally located nucleus containing normal chromatin. C2C12 cells contained large number of rough endoplasmic reticulum (RER), mitochondria and whorled structures within membrane bound vacuoles, which resembled myelin bodies (Fig. 3).

\section{CHIKV induced changes in infected C6/36 and C2C12 cells}

Cell contour of CHIKV infected C6/36 (Fig. 4, Panel I - A and B) and C2C12 cells (Fig. 5, Panel I - A) were unaltered during early stages of infection (0-6 h) compared to uninfected cells (Fig. 4, Panel I - E and F; Fig. 5, Panel I - G). The intercellular junctions of C6/36 cells (black arrows) were devoid of virions (Fig. 4, Panel I - A). Both infected and uninfected C6/36 cells contained vacuoles, which on higher magnification revealed the presence of granular and whorled contents (Fig. 4, Panel I - C, E and F). Additionally, cytopathic vacuoles type I (CPV I), which were distinct from vacuoles observed in uninfected cells, was observed in a few CHIKV infected C6/36 cells at 6 h p.i. (Fig. 4, Panel I - D). CPV I, measuring 705-1186 $\mathrm{nm}$ in diameter, were characterized by the presence of membranous spheres (diameter 48-75nm) lining the vacuoles. Similarly, CPV I complexes were noted as early as 6 h p.i. in infected C2C12 cells (Fig. 5, Panel I - E and F). These complexes were morphologically similar to the ones observed in CHIKV infected C6/36 cells measuring approximately $800-1150 \mathrm{~nm}$ in diameter. Intracellular organelles like the nuclei, mitochondria, Golgi complex and the RER in the infected and uninfected cells exhibited no noticeable differences during this stage (Fig.4, Panel I - A, B, E and F; Fig. 5, Panel I - B, C, D, G, H). Intercellular junctions (black arrows) in uninfected $\mathrm{C} 2 \mathrm{C} 12$ cells did not reveal the presence of viral nucleocapsids (Fig. 5, Panel I - I).

Electron micrographs of CHIKV infected C6/36 cells during the intermediate stages of infection $(12-18 \mathrm{~h})$ revealed that the cell morphology was unchanged (Fig. 4, Panel II - A). Intercellular junctions (white arrows) observed in some fields were completely free from viral nucleocapsids (Fig.4, Panel II - A). On the other hand, micrographs of other fields revealed that a few viral nucleocapsids (black arrows) were present in the majorly empty intercellular junctions (white arrows) (Fig. 4, Panel II - B). Furthermore, arrays of CHIKV nucleocapsids arranged in a single file were observed in other fields (Fig.4, Panel II - C). An increase in the number and distribution of CPV Is in infected C6/36 


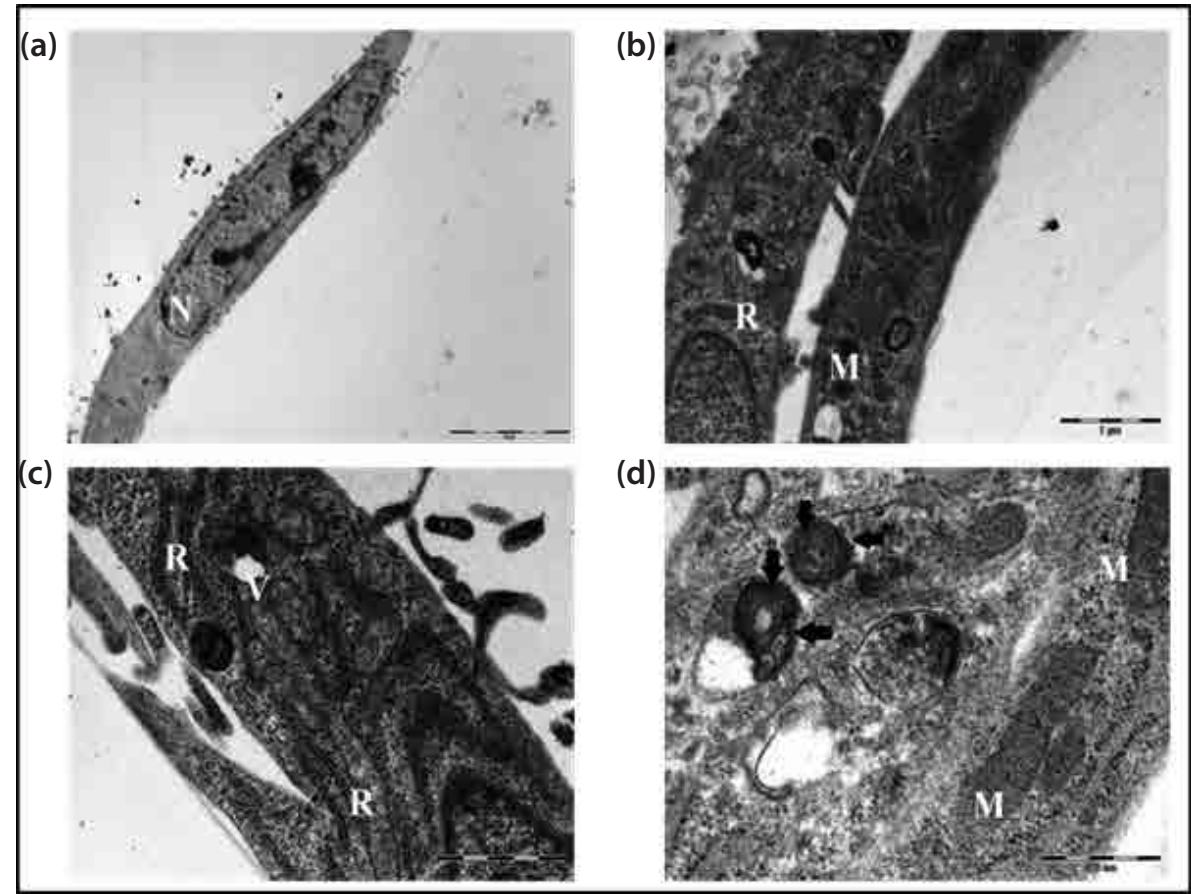

Fig. 3

Electron micrographs of normal $\mathrm{C} 2 \mathrm{C} 12$ cell

(a) $\mathrm{C} 2 \mathrm{C} 12$ cells are spindle shaped cells with defined nucleus (N). Bar represents $5 \mu \mathrm{m}$. (b) Higher magnification reveals rough endoplasmic reticulum (R) and mitochondria (M). Bar represents $1 \mu \mathrm{m}$. (c) A few vacuoles (V) are also observed upon higher magnification. Bar represents $1 \mu \mathrm{m}$. (d) Membrane bound whorled structures (black arrows) and mitochondria (M) are noted. Bar represents $500 \mathrm{~nm}$.

cells was noted during the intermediate stages of infection. Further, nucleocapsids (black arrows) were observed to be accumulated in these infected cells (Fig. 4, Panel II - D). Mature CHIKV particles were observed adjacent to the cell membrane enclosed within vacuoles (white arrows) (Fig. 4, Panel II - E). Lastly, single mature virions were observed to be budding out from the cell surface which consisted of an electron dense core surrounded by a less electron dense envelope (Fig. 4, Panel II - F). The spindle shape of the myoblasts remained intact as observed with uninfected cells during the intermediate stages of infection (Fig. 5, Panel II - A). Upon higher magnification, degraded forms of CPV I were noticed in most cells (Fig. 5, Panel II - B). Electron dense nucleocapsids were observed intermittently at intercellular junctions (white arrows) (Fig. 5, Panel II - C). Extensive budding of mature CHIKV particles (white arrows) was observed in most of the infected cell population (Fig. 5, Panel II - D and E). Besides, CHIKV particles were noticed migrating towards the cell membrane within vacuoles (black arrows) (Fig. 5, Panel II - E). As observed with infected C6/36 cells, budding virions at $\mathrm{C} 2 \mathrm{C} 12$ cell surface consisted of an electron dense core which was encapsulated by a less dense envelope (Fig. 5, Panel II - F).
With the progress of infection towards the late infection stages (24-30 h), the morphology of infected C6/36 cells was unaltered (Fig. 4, Panel III - A). On higher magnification, CPV I (Fig. 4, Panel III - B) and cytopathic vacuoles type II (CPV II) complexes (Fig. 4, Panel III - C) were observed in infected C6/36 cells. It was interesting to note that CPV II complexes outnumbered CPV Is during this infection period. CPV II complexes were characterized by smaller vacuoles, measuring 280-300 $\mathrm{nm}$ in diameter. Large numbers of these complexes were observed to cluster near the cell membrane (Fig. 4, Panel III - C). The cytoplasmic side of the CPV II vacuoles was surrounded by neatly arranged electron-dense viral nucleocapsids (30-40 $\mathrm{nm}$ in diameter). Similar to the intermediate stages of infection, aggregates of electron dense virions (white arrows) were found within infected C6/36 cells (Fig. 4, Panel III - C); albeit at higher frequencies. CHIKV nucleocapsids were seen arrayed in a single file in intercellular junctions (black arrows) (Fig. 4, Panel III - D). Mature progeny virus was found to exit cells either by exocytosis (Fig. 4, Panel III - E) or by budding (Fig. 4, Panel III - F).

Profound vacuole formation of the cytoplasm of CHIKV infected C2C12 cells (Fig. 5, Panel III - A) was the hallmark of CHIKV infection during the late infection stage 

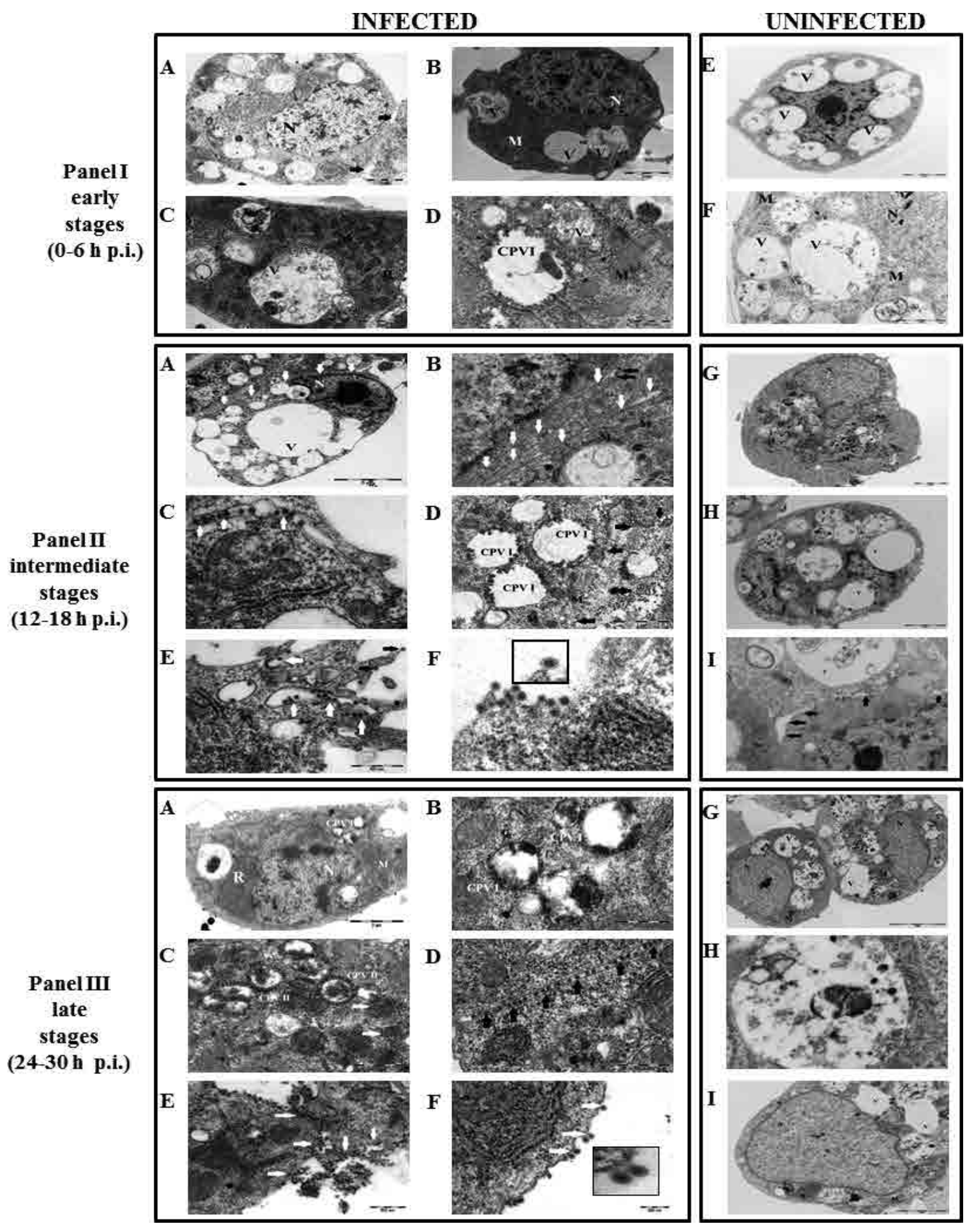

Fig. 4

Kinetics of CHIKV infection in C6/36 cells studied by transmission electron microscopy during early (0-6 h p.i.), intermediate (12-18 h p.i.) and late stages (24-30 h p.i.) of infection

Budding of mature CHIK virions was observed starting from intermediate stages (Panel II - F) which continued till 30 h p.i. (Panel III - F). Note that CHIKV infection did not lead to apoptosis in C6/36 cells until the end of the experiment (Panel III) (details provided in text). 


\section{INFECTED}
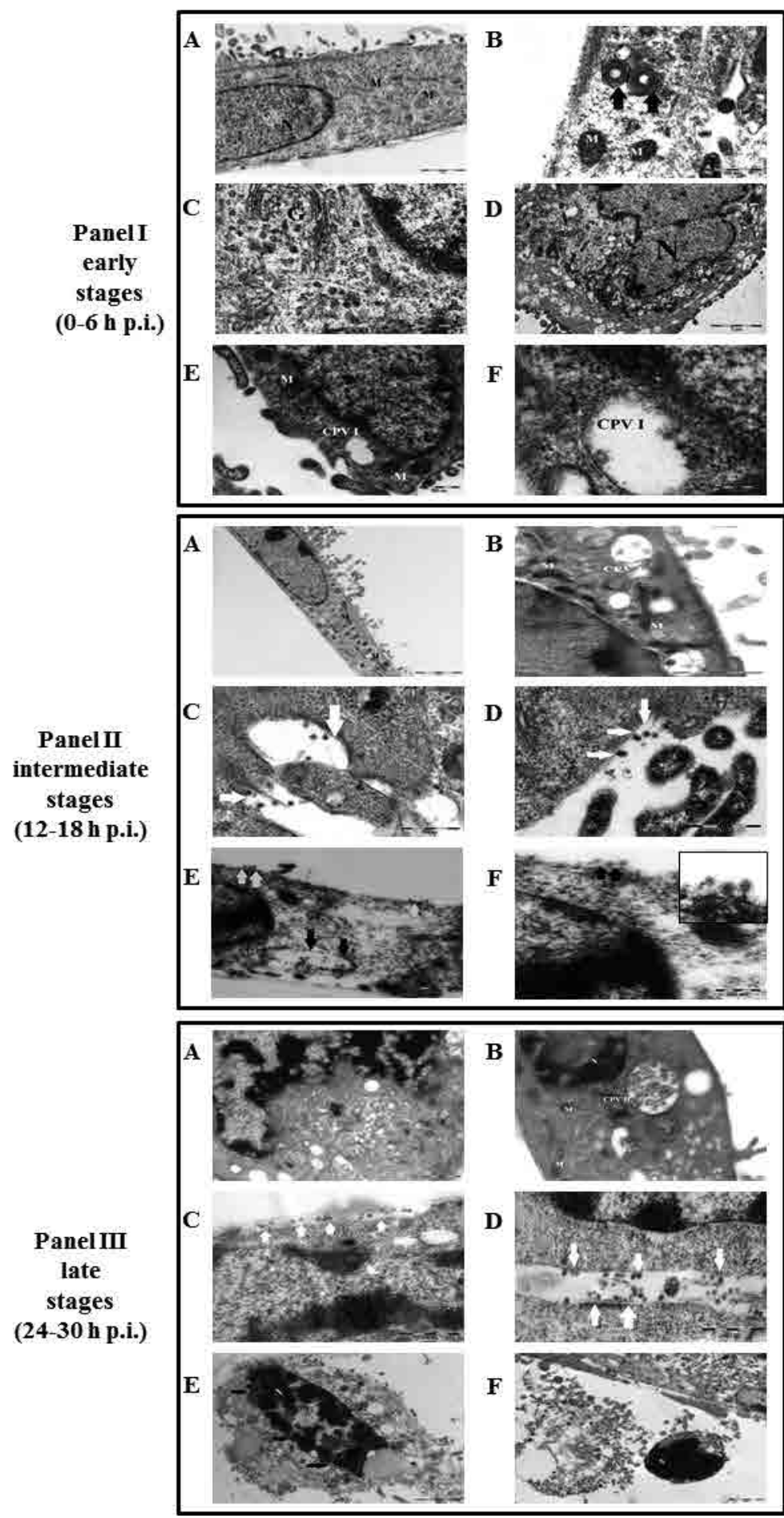

Fig. 5

\section{UNINFECTED}
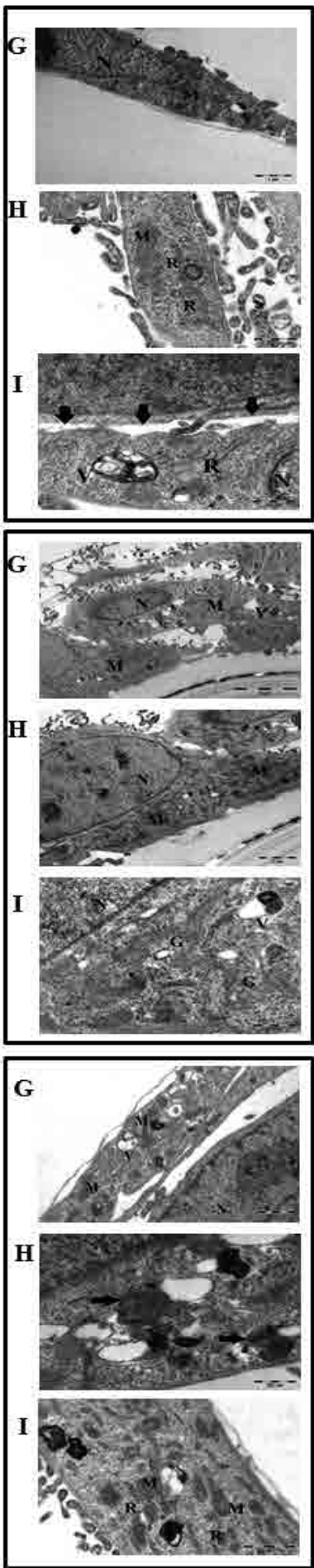

Kinetics of CHIKV infection in C2C12 cells studied by transmission electron microscopy during early (0-6 h p.i.), intermediate (12-18 h p.i.) and late stages (24-30 h p.i.) of infection

Budding of mature CHIK virions was observed starting from intermediate stages (Panel II - F). Exocytosis of mature CHIK virions was the preferred mode of egress during the late stages (Panel III - C) of infection. Classical features of apoptosis were observed in CHIKV infected C2C12 cells during the late stages of infection, leading to cell death (Panel III - A, E, F) (details provided in text). 
(24-30 h p.i.). Unlike CHIKV-infected C6/36 cells at the same stage of infection, CPV I was not seen in infected C2C12 cells. Instead the emergence of CPV II (270-300 nm) was noted in infected cells (Fig. 5, Panel III - B). CHIKV particles were seen aggregated below the cell membrane (white arrows) (Fig. 5, Panel III - C) and also in the intercellular junctions (white arrows) (Fig. 5, Panel III - D). Further, infected cells exhibited clumped chromatin within the nuclei, blebbing nuclear membrane and loss of cell membrane and cell lysis with the progress of time (Fig. 5, Panel III - E and F). At 30 h p.i., near complete lysis of cells was noted with the exception of few, which nevertheless appeared highly stressed (Fig. 5, Panel III - F). Upon higher magnification, it was noted that uninfected $\mathrm{C} 2 \mathrm{C} 12$ cells exhibited normal cell morphology (Fig. 5, Panel III - G, H, I) and vacuoles in these cells did not contain CHIKV particles (black arrows) (Fig. 5, Panel III - H). In contrast, there was no significant difference between the cell contours of infected and uninfected C6/36 cells during the late infection stage (Fig. 4, Panel
III - A, G, H and I). Further, no cytolysis was observed in CHIKV infected C6/36 cells during this period (Fig. 4, Panel III - A to F).

\section{Actin architecture in uninfected C2C12 cells}

Actin stress fibers in normal C2C12 cells, which were labelled with fluorochrome Cy 3 were stained bright red and seen to span the entire cell circumference and also present at the cell perimeter (Fig. 6). On higher magnification, it was noted that the nucleus did not stain positive for actin. The typical spindle shape appearance of $\mathrm{C} 2 \mathrm{C} 12$ cells could be seen as well (Fig. 6).

\section{Tubulin architecture in uninfected C2C12 cells}

The microtubule framework of normal C2C12 cells, which were labelled with Alexa Fluor ${ }^{\circledast} 488$, appeared apple green under confocal microscopy (Fig. 6). Higher magni-

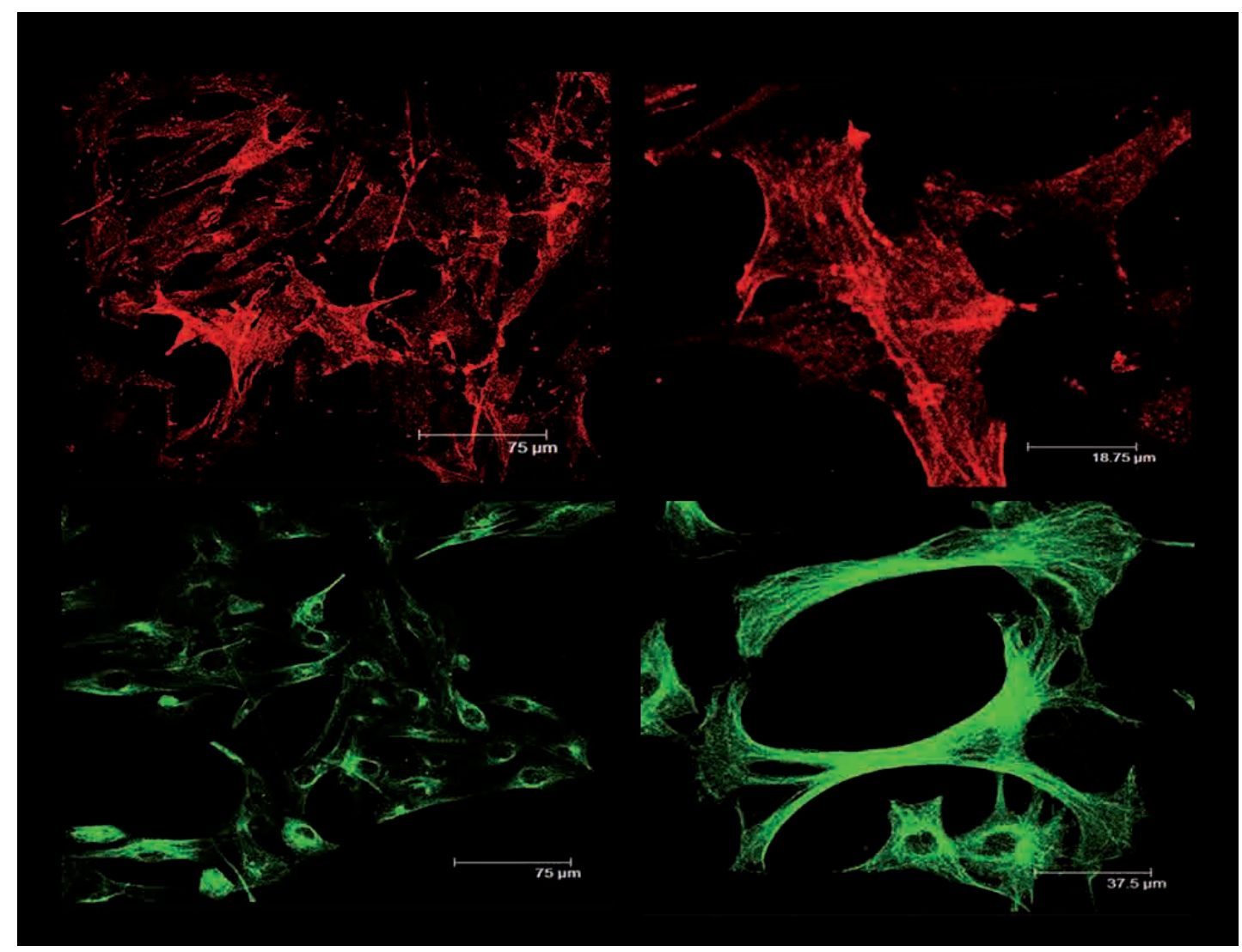

Fig. 6

Actin cytoskeletal and $\alpha$-tubulin architecture in normal (uninfected) C2C12 cells

The actin (red) and $\alpha$-tubulin (green) arrangement in uninfected C2C12 cells. Panel A represents a lower magnification (scale $75 \mu \mathrm{m}$ ) to capture a wider field of cytoskeletal protein staining in C2C12 cells. Panel B represents a higher magnification which shows actin stress fibres and $\alpha$-tubulin network in individual cells (scale $18.75 \mu \mathrm{m}$ and $37.5 \mu \mathrm{m}$ respectively). Note that the cell periphery is positive for actin. Neither actin nor $\alpha$-tubulin are present in the nuclei. 
fication revealed absence of microtubules in the nucleus. The distribution of a-tubulin was observed to be denser in the central region of the spindle shaped myoblasts than the apical ends (Fig. 6).

CHIKV induced changes in the actin and $\alpha$-tubulin cytoskeletal architecture in C2C12 cells

Alterations in the actin and $\alpha$-tubulin architecture of C2C12 cells due to CHIKV infection was observed during early $(0-6 \mathrm{~h})$, intermediate $(12-18 \mathrm{~h})$ and late $(24-30 \mathrm{~h})$ stages of infection.

The actin and $\alpha$-tubulin framework of CHIKV-infected $\mathrm{C} 2 \mathrm{C} 12$ cells did not vary significantly from that observed in uninfected cells during the early stages of CHIKV infection (Fig. 7, Panel I; Fig. 8, Panel I). CHIKV antigen was observed in few cells at this stage.

A drastic change in the appearance of infected C2C12 cells from the normal spindle shape was noticed during the intermediate stages of infection, especially towards $18 \mathrm{~h}$ p.i. (Fig. 7, Panel II; Fig. 8, Panel II). Actin positive filamentous extensions (Fig. 7, Panel II) and long a-tubulin positive extensions were seen in infected cells (Fig. 8, Panel II). At higher magnification, two types of cell extensions were observed; long tubulin positive extensions (white solid arrows) and short tubulin negative ones (white dashed arrows) (Fig. 9). It was also noticed that infected cells which expressed lesser proportion of CHIKV antigen had no observable differences in cell morphologies with uninfected control cells (Fig. 7, Panel II; Fig. 8, Panel II).

The actin and microtubulin frameworks in CHIKV infected $\mathrm{C} 2 \mathrm{C} 12$ cells were found to be completely disoriented during the late stages of infection (Fig. 7, Panel III; Fig. 8, Panel III). Cells were either completely rounded in appearance with numerous actin positive filamentous extensions (Fig. 7, Panel III) or were shrunken with multiple extensions towards the apical ends (Fig. 8, Panel III). There was a drastic reduction in the number of $\mathrm{CHIKV}$ infected $\mathrm{C} 2 \mathrm{C} 12$ cells observed at this stage. Active co-localization of CHIKV and cytoskeletal proteins actin and $\alpha$-tubulin was noted in infected C2C12 cells (merged panel) during the intermediate and late stages of infection (Fig. 7, Panels II and III; Fig. 8, Panels II and III). The actin and $\alpha$-tubulin network in uninfected cells remained unaltered at 30 h p.i. (Fig. 7; Fig. 8).

\section{Discussion}

Ultrastructural changes effected in a host cell during viral replication provide insights into the disease pathophysiology. Besides, viruses are known to interact and utilize the host cytoskeleton or cytoskeletal elements for their internalization, transport, replication, assembly, and/or release. Viral interaction with host cytoskeletal proteins results in alterations in the cytoskeletal architecture, which again varies between viruses and cell types. Alphaviruses are known to enter host cells by receptor-mediated endocytosis, replicate in the cytoplasm and exit by exocytosis or budding (Marquardt $e t$ al., 1993; Strauss and Strauss, 1994). Studies to document the complete alphaviral replication event in relation to the course of infection, at the ultrastructural level, have been majorly restricted to SINV and SFV (Peränen and Kääriäinen, 1991; Jose et al., 2017). Very few studies deal with and compare the ultrastructural changes due to CHIKV replication in mosquito cells which get persistently infected (Chen et al., 2013) and myosatellite cells, where cytolysis is observed (Hussain et al., 2016).

Transmission electron micrographs in the present study revealed that negatively stained CHIKV DRDE-06 were spherical, measuring $\sim 58 \mathrm{~nm}$ in diameter. Each virion was composed of a core, measuring $\sim 38 \mathrm{~nm}$ in diameter, surrounded by an electron dense envelope. Earlier studies have reported that the virion core diameter was 25-30 $\mathrm{nm}$ and the total diameter was $42 \mathrm{~nm}$ (Simizu et al., 1984). However, later TEM analyses have reported that CHIKV cores measured approximately $40 \mathrm{~nm}$, with the total diameter being $\sim 60 \mathrm{~nm}$, which is consistent with the size of other alphaviruses (Lee et al., 2013; Saraswat et al., 2016).

The infection pattern of CHIKV in C2C12 and C6/36 cell lines was distinctly unique at the ultrastructural level at various time points after infection. CHIKV infection of $\mathrm{C} 2 \mathrm{C} 12$ cells resulted in cell death during the late infection stage. Classical apoptotic features which involved condensed chromatin, extensive cytoplasmic vacuolation, blebbing of the nuclear envelope (Ziegler and Groscurth, 2004; Shubin et al., 2016) preceded cell lysis in CHIKV-infected C2C12 cells. Rapid onset of apoptosis at the cellular level, as a result of CHIKV infection, has been well studied in vivo and in vitro (Krejbich-Trotot et al., 2011; Joubert et al., 2012). Although apoptosis was initially suggested to be a protective measure by the host to limit virus production and spread, it is now understood that the host apoptotic machinery can be hijacked by many different viruses including alphaviruses which is detrimental to the host (Long and Heise, 2015). Further, in vitro experiments have revealed that CHIKV hides in apoptotic blebs of infected cells, which upon subsequent release infect neighbouring cells and thus escalate infection process (Krejbich-Trotot et al., 2011). CHIKV infection of C6/36 cells, on the other hand, exhibited time course evolution of virus induced morphological changes which have been reported earlier (Chen et al., 2013).

Self-renewal of satellite cells has been proposed as one of the principal mechanisms to effectively maintain a viable satellite cell pool, thereby facilitating muscle regeneration after repeated episodes of damage (Charge and Rudnicki, 2004; Wozniak et al., 2005). Activated satellite cells, termed 

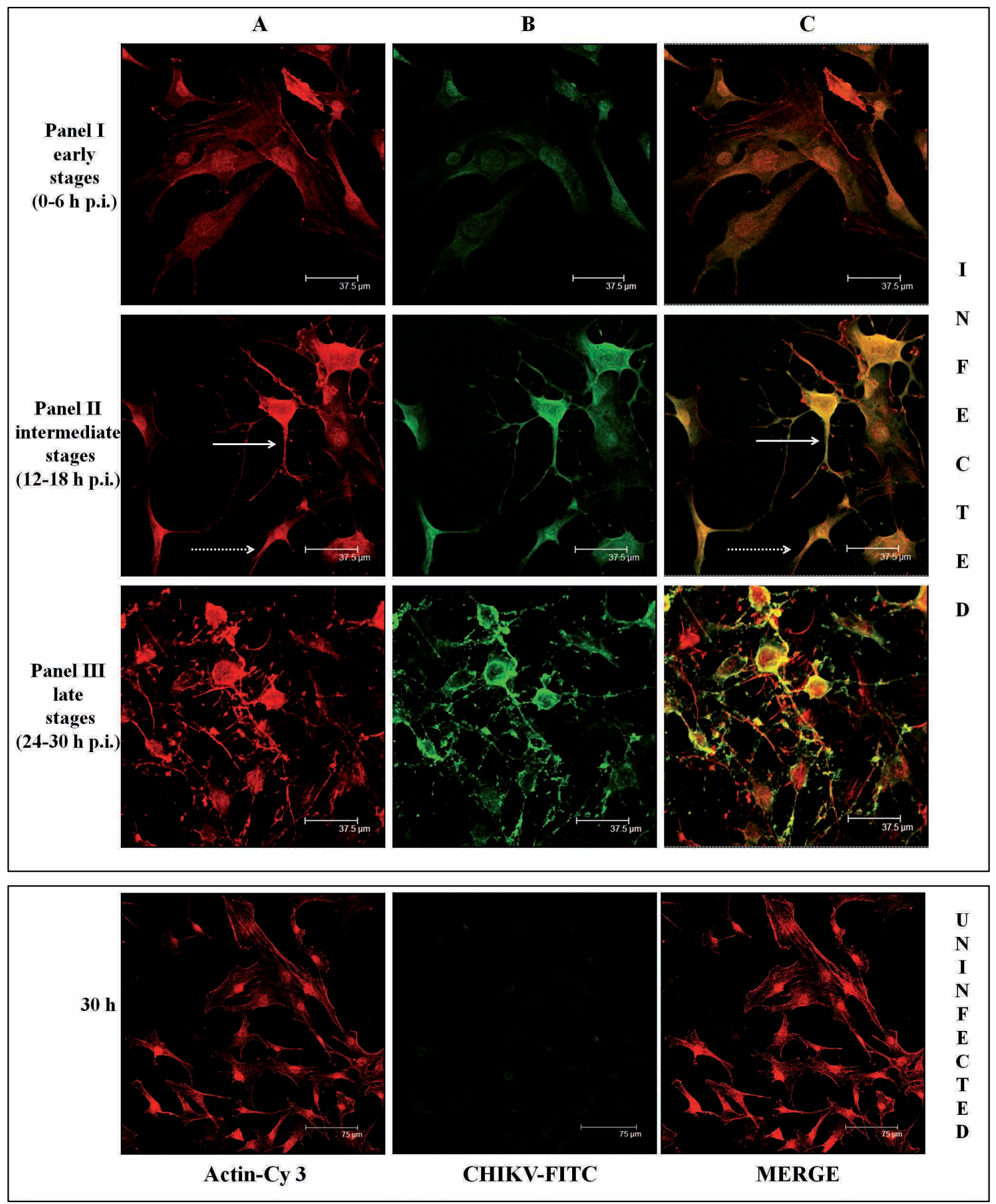

Fig. 7

Changes in the actin cytoskeletal architecture in CHIKV infected C2C12 cells

Representative images of early (Panel I), intermediate (Panel II) and late infection stage (Panel III). Panel I: Infected C2C12 cells exhibited normal spindle shape. Actin stress fibres were observed. Panel II: Note the emergence of actin positive extensions (white solid arrow) in infected cells with altered morphology. On the other hand, cells that expressed lesser CHIKV-FITC (green) fluorescence did not exhibit these extensions (white dotted arrow). Panel III: Infected cells were rounded in appearance, brightly expressed CHIKV antigen and the actin cytoskeletal architecture was completely lost. Scale represents $37.5 \mu \mathrm{m}$. Note that uninfected C2C12 cells at $30 \mathrm{~h}$ neither exhibited any change in morphology nor contained any extensions. Scale represents $75 \mu \mathrm{m}$. 

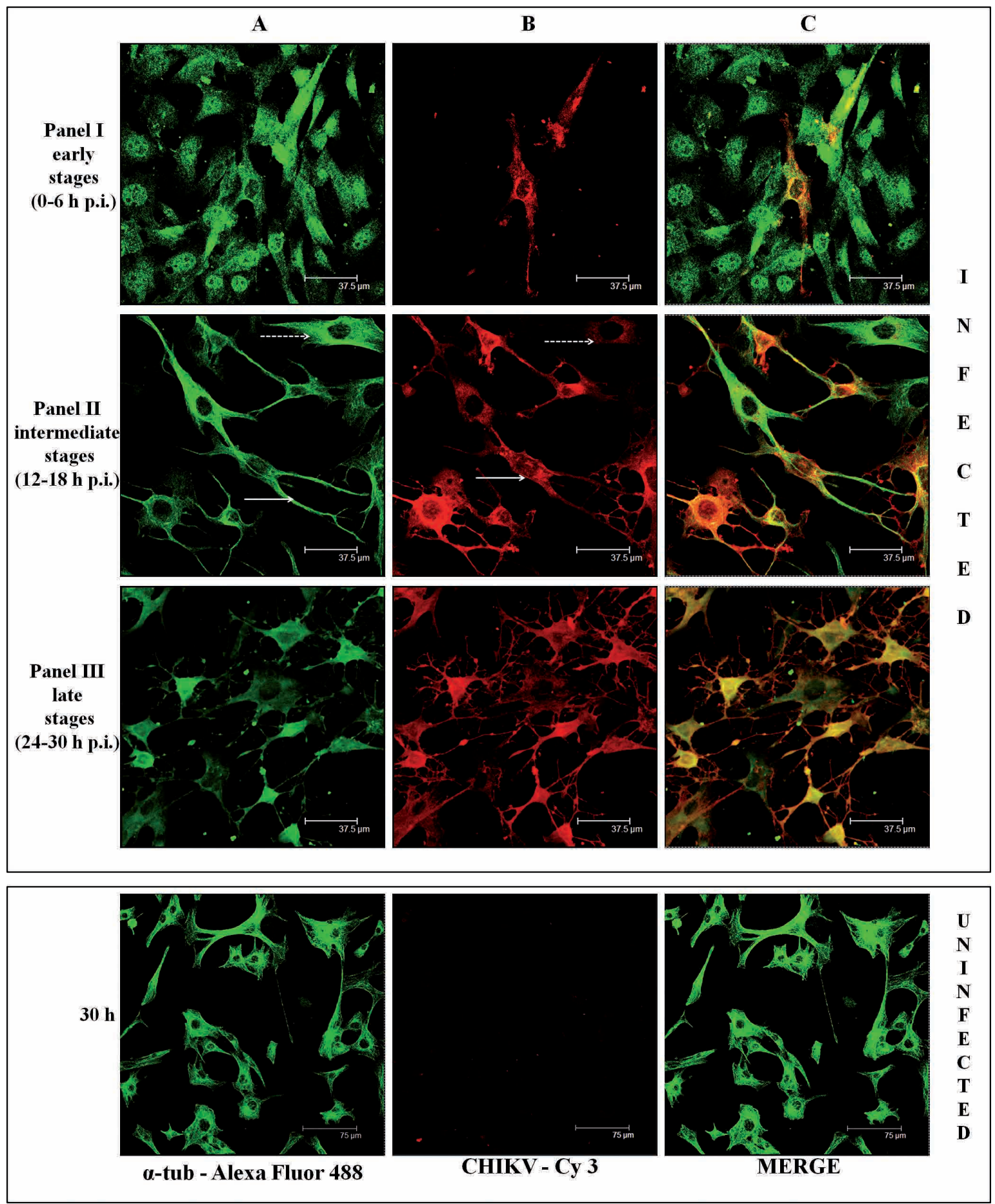

Fig. 8

Changes in the microtubule architecture in $\mathrm{CHIKV}$ infected $\mathrm{C} 2 \mathrm{C} 12$ cells

Representative images of early (Panel I), intermediate (Panel II) and late infection stage (Panel III). Panel I: Infected C2C12 cells exhibited normal spindle shape. Only a few cells expressed CHIKV antigen. Panel II: The intensity of CHIKV-Cy3 fluorescence increased with time and was observed across all cells. Note the changes in $\alpha$-tubulin organisation and cell morphology in CHIKV infected C2C12 cells. $\alpha$-tubulin positive extensions were observed in infected cells (white solid arrow) with altered morphology. Cells that expressed lesser CHIKV-Cy3 (red) fluorescence did not contain these extensions (white dotted arrow). Panel III: CHIKV infected C2C12 cells were shrunken in appearance and contained numerous extensions originating from the cell surface. Scale represents $37.5 \mu \mathrm{m}$. Note that uninfected C2C12 cells at $30 \mathrm{~h}$ neither exhibited any change in morphology nor exhibited these extensions. Scale represents $75 \mu \mathrm{m}$. 

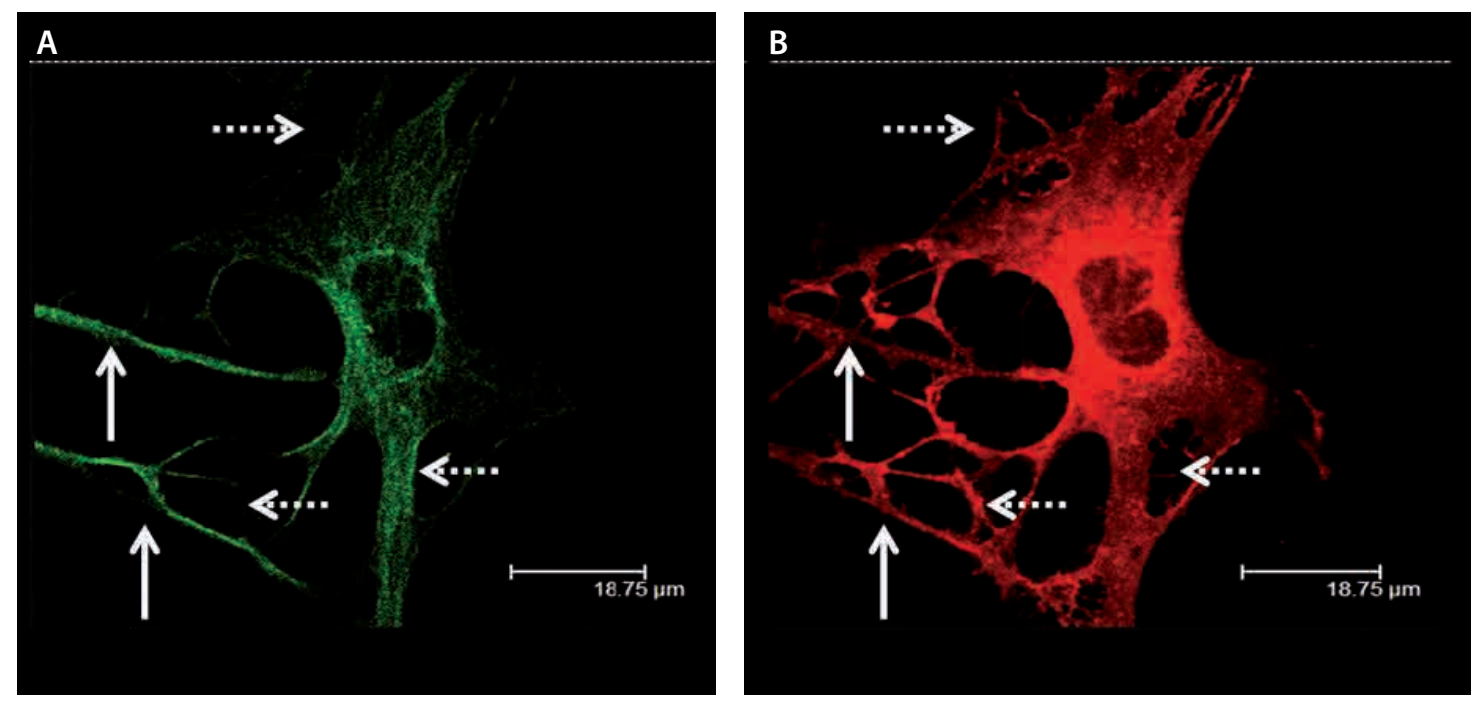

Fig. 9

CHIKV induced changes in $\mathrm{C} 2 \mathrm{C} 12$ cells during intermediate stages of infection

Upon higher magnification $\alpha$-tubulin positive long extensions (white solid arrows) were observed in Panel A. $\alpha$-tubulin negative short extensions were seen in Panel B (white dashed arrows). Scale represents $18.75 \mu \mathrm{m}$.

myoblasts, then proliferate massively to generate the myogenic progenitors needed for muscle regeneration (Zammit et al., 2006). Murine myoblast cells, C2C12, are derived from "satellite cells" (Burattini et al., 2004). Selective CHIKV infection of human myosatellite cells have been reported earlier (Ozden et al., 2007). Inappropriate apoptosis of myoblasts leads to muscle degeneration associated with various muscular dystrophies and atrophies. Further, the pool of available myoblasts for myogenesis has been shown to be important for the maintenance of healthy muscle (Li et al., 2012). A prospective study on chikungunya patients after 36 months of the actual disease reported myalgia as an additional symptom with arthralgia (Schilte et al., 2013). With the selective CHIKV infection of muscle satellite cells being reported earlier, we report CHIKV induced ultrastructural changes in myoblast cells leading to apoptosis in the present study. Further experiments can delineate whether CHIKV persists in the satellite cell/myoblast pool, leading to the recurrence of myalgia in infected humans, since the disease pathophysiology still remains to be elucidated.

Ultrastructural changes noted in CHIKV infected C2C12 cells by electron microscopy elicited the need to further investigate the consequent alterations in the cytoskeletal framework post CHIKV infection. The intermediate stages of CHIKV infection resulted in the induction of actin positive filopodia-like extensions, which were characterised by a thick root and were branched at their distal parts. Disassembly of the actin cytoskeleton, resulting in the disappearance of actin stress fibers in CHIKV infected C2C12 cells, was also observed during this stage. Simultaneously, long, tubulin positive and short, tubulin negative extensions were observed in CHIKV infected C2C12 cells during this stage, albeit tubulin was better expressed in $\mathrm{C} 2 \mathrm{C} 12$ cells which expressed lower levels of CHIKV. The late stages of CHIKV infection was marked by shrinkage of cells and subsequently led to cell death. Electron microscopy results revealed onset of apoptosis around this time as the cause of cell death due to CHIKV infection. It was also observed that the final stages of CHIKV infection correlated with a decreased level of fluorescence staining for the cytoskeletal proteins actin and tubulin.

Alphavirus-induced formation of filopodium-like extensions (actin positive) in infected cells is well documented (Birdwell et al., 1973; Pavan et al., 1987). Mammalian cells transfected with the non-structural protein 1 (nsp1) of SINV and SFV showed induction of large number of filopodia-like structures (Laakkonen et al., 1998; Martinez et al., 2014). The same phenomenon (filopodium like extensions) was observed in the present study during the intermediate stages of CHIKV infection i.e. $12-18 \mathrm{~h}$ p.i. The role of CHIKV nsp1 exclusively in the expression of filopodia needs to be ascertained.

Furthermore, two morphologically distinct types of extensions were observed in CHIKV infected C2C12 cells during the intermediate infection stages; tubulin-positive extensions that were significantly longer and tubulinnegative extensions that were relatively short. In an earlier study, Martinez et al. (2014), reported that SINV infection of Vero cells resulted in similar sort of plasma membrane extensions. In their study, the tubulin positive long exten- 
sions were also positive for actin. The authors concluded that alphavirus infection induced two distinct types of extensions: shorter, tubulin-negative extensions and longer, tubulin-positive extensions that participate in active virus budding. Further, the role of the longer tubulin positive extensions in mediating cell-to-cell virus particle transfer was revealed using correlative light and electron microscopy (CLEM) and live-cell imaging. Electron micrographs in the present study clearly show that CHIKV budding occurs during the intermediate stages of infection in $\mathrm{C} 2 \mathrm{C} 12$ cells. Therefore, it appears that the longer tubulin positive extensions observed during the intermediate stages of CHIKV infection in $\mathrm{C} 2 \mathrm{C} 12$ cells might be involved in transfer of virus to non-infected cells; a possibly conserved alphaviral mechanism of virus transfer and infection.

The indispensible role of intact actin microfilaments and microtubules, for a post-fusion step of CHIKV life cycle has been reported (Bernard et al., 2010). Treatment of HEK 293T cells with cytochalasin $\mathrm{D}$, a fungal compound that disrupts actin filaments and nocodazole, an inhibitor of microtubule polymerization reduced CHIKV infection. Our observations also reveal co-localization between CHIKV and cytoskeletal proteins, actin and tubulin during the course of CHIKV infection in $\mathrm{C} 2 \mathrm{C} 12$ cells. Although the present study did not include experiments that probed the effects of actin/tubulin depletion on CHIKV infection, the confocal microscopy observations are clearly indicative of the close association between CHIKV infection and cytoskeletal proteins.

The present study therefore revealed that CHIKV infection in $\mathrm{C} 2 \mathrm{C} 12$ cells triggered apoptosis induced cell death whereas the virus completed its life cycle in C6/36 cells without causing significant changes at the ultrastructural level. It was interesting to note the selective pathophysiology at the ultrastructural level emanating due to the infection of the same virus in two different cell lines - one mammalian and the other an insect cell line. The subversion of cytoskeletal actin and tubulin by CHIKV in C2C12 cells was also studied using confocal microscopy. CHIKV induced morphological changes observed were in concurrence with those reported earlier for other alphaviruses. Co-localization between CHIKV and actin and tubulin revealed that the virus was actively associated with these cytoskeletal proteins during replication within $\mathrm{C} 2 \mathrm{C} 12$ cells. Further experiments should explain whether virus induced cell death in infected myoblasts triggers inflammation accountable for subsequent myalgia in CHIKV-infected human beings.

It is evident that almost all viruses interact with the host cytoskeleton or cytoskeletal elements during some stage in their life cycle. While viruses often employ host microfilaments to aid their entry or release, intermediate filaments and microtubules are used most often for genome replication or virion assembly. To conclude, as Radtke, Katinka and Sodeik (2006) stated in their review on viruses and cytoskeleton, "viruses have been trained as cell biologists for millions of years, and thus teach us unexpected molecular lessons about intracellular itineraries."

Acknowledgments. The authors acknowledge the fellowship support from Council of Scientific and Industrial Research, Government of India (GOI) awarded to AG (Grant No. 19-12/2010 (I) EU-IV, dated June 28, 2011) and the research grant awarded by the Department of Biotechnology, GOI [102/IFD/SAN/5323/20122013 dated March 15, 2013] to AD.

\section{References}

Bernard E, Solignat M, Gay B, Chazal N, Higgs S, Devaux C, Briant L (2010): Endocytosis of chikungunya virus into mammalian cells: role of clathrin and early endosomal compartments. PLoS One 5, e11479. https://doi.org/10.1371/ journal.pone.0011479

Birdwell CR, Strauss EG, Strauss JH (1973): Replication of Sindbis virus: III. An electron microscopic study of virus maturation using the surface replica technique. Virology 56 , 429-438. https://doi.org/10.1016/0042-6822(73)90047-0

Burattini S, Ferri P, Battistelli M, Curci R, Luchetti F, Falcieri E (2004): C2C12 murine myoblasts as a model of skeletal muscle development: morpho-functional characterization. Eur. J. Histochem. 48, 223-233.

Chargé SB, Rudnicki MA (2004): Cellular and molecular regulation of muscle regeneration. Physiol. Rev. 84, 209-238. https:// doi.org/10.1152/physrev.00019.2003

Chen KC, Kam YW, Lin RT, Ng MM, Ng LF, Chu JJ (2013): Comparative analysis of the genome sequences and replication profiles of chikungunya virus isolates within the East, Central and South African (ECSA) lineage. Virol. J. 10, 169. https://doi.org/10.1186/1743-422X-10-169

Das S, Laxminarayana SV, Chandra N, Ravi V, Desai A (2009): Heat shock protein 70 on Neuro2a cells is a putative receptor for Japanese encephalitis virus. Virology 385, 47-57. https:// doi.org/10.1016/j.virol.2008.10.025

Grimley PM, Levin JG, Berezesky IK, Friedman RM (1972): Specific membranous structures associated with the replication of group A arboviruses. J. Virol. 10, 492-503.

Hussain KM, Lee RC, Ng MM, Chu JJ (2016): Establishment of a novel primary human skeletal myoblast cellular model for Chikungunya virus infection and pathogenesis. Sci. Rep. 6, 21406. https://doi.org/10.1038/srep21406

Jose J, Taylor AB, Kuhn RJ (2017): Spatial and temporal analysis of alphavirus replication and assembly in mammalian and mosquito cells. MBio 8, e02294-16. https://doi. org/10.1128/mBio.02294-16

Joubert PE, Werneke SW, de la Calle C, Guivel-Benhassine F, Giodini A, Peduto L, Levine B, Schwartz O, Lenschow DJ, Albert ML (2012): Chikungunya virus-induced autophagy delays caspase-dependent cell death. J. Exp. Med. 209, 1029-1047. https://doi.org/10.1084/ jem.20110996 
Krejbich-Trotot P, Denizot M, Hoarau JJ, Jaffar-Bandjee MC, Das T, Gasque P (2011): Chikungunya virus mobilizes the apoptotic machinery to invade host cell defenses. FASEB J. 25, 314-325. https://doi.org/10.1096/ff.10-164178

Kumar A, Mamidi P, Das I, Nayak TK, Kumar S, Chhatai J, Chattopadhyay S, Suryawanshi AR, Chattopadhyay S (2014): A novel 2006 Indian outbreak strain of Chikungunya virus exhibits different pattern of infection as compared to prototype strain. PLoS One 9, e85714. https://doi. org/10.1371/journal.pone.0085714

Laakkonen P, Auvinen P, Kujala P, Kääriäinen L (1998): Alphavirus replicase protein NSP1 induces filopodia and rearrangement of actin filaments. J. Virol. 72, 10265-10269.

Lee RC, Hapuarachchi HC, Chen KC, Hussain KM, Chen H, Low SL, Ng LC, Lin R, Ng MM, Chu JJ (2013): Mosquito cellular factors and functions in mediating the infectious entry of chikungunya virus. PLoS Negl. Trop. Dis. 7, e2050. https:// doi.org/10.1371/journal.pntd.0002050

Li Z, Gilbert JA, Zhang Y, Zhang M, Qiu Q, Ramanujan K, Shavlakadze T, Eash JK, Scaramozza A, Goddeeris MM, Kirsch DG, Campbell KP, Brack AS, Glass DJ (2012): An HMGA2-IGF2BP2 axis regulates myoblast proliferation and myogenesis. Dev. Cell. 23, 1176-1188. https://doi. org/10.1016/j.devcel.2012.10.019

Li YG, Siripanyaphinyo U, Tumkosit U, Noranate N, A-nuegoonpipat A, Tao R, Kurosu T, Ikuta K, Takeda N, Anantapreecha S (2013): Chikungunya virus induces a more moderate cytopathic effect in mosquito cells than in mammalian cells. Intervirology 56, 6-12. https://doi. org/10.1159/000339985

Long KM, Heise MT (2015): Protective and pathogenic responses to chikungunya virus infection. Curr. Trop. Med. Rep. 2, 13-21. https://doi.org/10.1007/s40475-015-0037-z

Marquardt MT, Phalen T, Kielian M (1993): Cholesterol is required in the exit pathway of Semliki forest virus. J. Cell Biol. 123, 57-65. https://doi.org/10.1083/jcb.123.1.57

Martinez MG, Snapp EL, Perumal GS, Macaluso FP, Kielian M (2014): Imaging the Alphavirus exit pathway. J. Virol. 88, 6922-6233. https://doi.org/10.1128/JVI.00592-14

Ozden S, Huerre M, Riviere JP, Coffey LL, Afonso PV, Mouly V, de Monredon J, Roger JC, El Amrani M, Yvin JL, Jaffar MC, Frenkiel MP, Sourisseau M, Schwartz O, Butler-Browne G, Desprès P, Gessain A, Ceccaldi PE (2007): Human muscle satellite cells as targets of Chikungunya virus infection. PLoS One 2, e527. https://doi.org/10.1371/ journal.pone.0000527

Pavan A, Lotti LV, Torrisi MR, Migliaccio G, Bonatti S (1987): Regional distribution of Sindbis virus glycoproteins on the plasma membrane of infected baby hamster kidney cells. Exp. Cell Res. 168, 53-62. https://doi.org/10.1016/0014$\underline{4827(87) 90415-0}$
Peränen J, Kääriäinen L (1991): Biogenesis of type I cytopathic vacuoles in Semliki Forest virus-infected BHK cells. J. Virol. 65, 1623-1627.

Radtke K, Döhner K, Sodeik B (2006): Viral interactions with the cytoskeleton: a hitchhiker's guide to the cell. Cell Microbiol. 8, 387-400. https://doi.org/10.1111/j.14625822.2005.00679.x

Reddy V, Ravi V, Desai A, Parida M, Powers AM, Johnson BW (2012): Utility of IgM ELISA, TaqMan real-time PCR, reverse transcription PCR, and RT-LAMP assay for the diagnosis of Chikungunya fever. J. Med. Virol. 84, 1771-1778. https://doi.org/10.1002/jmv.23406

Ryman KD, Klimstra WB (2008): Host responses to alphavirus infection. Immunol. Rev. 225, 27-45. https://doi. org/10.1111/j.1600-065X.2008.00670.x

Saraswat S, Athmaram TN, Parida M, Agarwal A, Saha A, Dash PK (2016): Expression and characterization of yeast derived Chikungunya virus like particles (CHIK-VLPs) and its evaluation as a potential vaccine candidate. PLoS Negl. Trop. Dis. 10, e0004782. https://doi.org/10.1371/journal. pntd.0004782

Schilte C, Staikowsky F, Couderc T, Madec Y, Carpentier F, Kassab S, Albert ML, Lecuit M, Michault A (2013): Chikungunya virus-associated long-term arthralgia: a 36-month prospective longitudinal study. PLoS Negl. Trop. Dis. 7, e2137. https://doi.org/10.1371/journal.pntd.0002137

Shubin AV, Demidyuk IV, Komissarov AA, Rafieva LM, Kostrov SV (2016): Cytoplasmic vacuolization in cell death and survival. Oncotarget. 7, 55863. https://doi.org/10.18632/ oncotarget. 10150

Simizu B, Yamamoto K, Hashimoto K, Ogata T (1984): Structural proteins of Chikungunya virus. J. Virol. 51, 254-258.

Solignat M, Gay B, Higgs S, Briant L, Devaux C (2009): Replication cycle of chikungunya: a re-emerging arbovirus. Virology 393, 183-197. https://doi.org/10.1016/j.virol.2009.07.024

Strauss JH, Strauss EG (1994): The Alphaviruses: gene expression, replication, and evolution. Microbiol. Rev. 58, 491-562.

Wickstead B, Gull K (2011): The evolution of the cytoskeleton. J. Cell Biol. 194, 513-525. https://doi.org/10.1083/jcb.201102065

Wozniak AC, Kong J, Bock E, Pilipowicz O, Anderson JE (2005): Signalling satellite-cell activation in skeletal muscle: Markers, models, stretch, and potential alternate pathways. Muscle Nerve 31, 283-300. https://doi.org/10.1002/ mus.20263

Zammit PS, Partridge TA, Yablonka-Reuveni Z (2006): The skeletal muscle satellite cell: the stem cell that came in from the cold. J. Histochem. Cytochem. 54, 1177-1191. https://doi. org/10.1369/jhc.6R6995.2006

Ziegler U, Groscurth P (2004): Morphological features of cell death. News Physiol. Sci. 19, 124-128. https://doi.org/10.1152/ nips.01519.2004 